\title{
Presentación
}

Entre la aparición del breve texto que presentamos a continuación y la del el ejemplar en turno -32 años-, hemos visto aparecer, en México, alrededor o más de 30 reformas, adiciones, reglamentos y programas orientados a la mejora educativa del país.

El comentario que sigue, en particular, tomaba el pulso a la reciente Revolución educativa que emprendió el entonces secretario del ramo, Jesús Reyes Heroles, a tres años de su puesta en marcha.

La componenda a la que alude tenía el propósito de garantizar la educación básica universal mediante la ampliación de la cobertura a 10 ańos obligatorios, en un ciclo que articularía los niveles de preescolar, primaria y secundaria; elevar la calidad de la educación a través del mejoramiento de la infraestructura, los materiales escolares y la participación social; especializar la formación del magisterio, lo que se patentó en la creación de la Universidad Pedagógica Nacional (UPN), a fin de mejorar la calidad de la educación a través de sus mentores y hacer más eficiente la inversión y el aprovechamiento de los recursos, lo que se lograría mediante un cambio de orientación administrativa, pasando de la desconcentración del gasto y el diseño curricular federales, a su descentralización hacia los estados de la República.

Aunque la intención y el gasto habían sido notables, la fuerza del Estado no alcanzó para concretar los objetivos planteados: la profunda crisis económica que afectó al país en los ochenta llevó su impronta al sector educativo con recortes presupuestales (de 81865.4 millones de pesos, en 1982, a 46482.5 en 1984), lo que culminó, hacia finales de la década, con un significativo grupo de población que no podía acceder o abandonaba el sistema escolar, mientras que al interior de las aulas se provocaba una progresiva discriminación interna y una caída de la calidad de los aprendizajes, sobre todo entre los grupos de población social, económica y culturalmente relegados, los que constituían la nueva población objetivo que se pretendía incorporar al sistema. 
Esto se percibe, en el pronunciamiento que sigue, como una muerte por "inanición" de la que hubiera nacido como una "Revolución educativa".

Es significativo recordar, también, que el texto aparece luego de más de 20 años de análisis de las falencias, los quiebres y de innumerables propuestas acerca de la educación que requería el país por parte de pioneros estudiosos en la materia y otros actores sociales, mientras que, a raíz del terremoto que sacudió la Ciudad de México en septiembre de 1985, la historia de la ciudadanía daría un vuelco radical cuando se puso de manifiesto la enorme solidaridad y la capacidad de organización espontánea de la sociedad civil en las acciones de rescate y reconstrucción de la capital y las ciudades más afectadas, así como en el cuestionamiento frontal de las políticas públicas. Todo esto, aparentemente, provoca en el grupo editor de esta revista la percepción de una "revolución de la organicidad social", así como a rescatar las exigencias derivadas de la investigación acerca de "poner el sistema educativo al servicio del alumno y de la sociedad; poner al maestro en el centro del proceso educativo, y centrar la educación en un saber integrador, significativo ... transformador", y añadiríamos, verdaderamente revolucionario.

A propósito de la muy reciente publicación del, como ha quedado sugerido, no necesariamente nuevo Modelo educativo, 2016 y de su Propuesta curricular, perecería otra vez que, finalmente, los resultados de la investigación educativa de este país se han hecho eco en el diseño de la política pública.

Ojalá que, pese a los recientes recortes en el presupuesto para la educación de los mexicanos, pese a los vacíos e incertidumbres que aún se resienten tanto en el propio modelo como en su ruta de implementación y financiamiento - uno, muy sensible, por cierto, acerca de las escuelas normales y la formación del magisterio-, pese al histórico divorcio entre las reformas y los hechos, nos encaminemos a un proceso que nos permita rehacer el tejido social, en una "revolución copernicana" nacida de la satisfacción que genere el proceso educativo entre sus principales actores, para construir, a partir de ello, el consenso sobre un concepto de nación que incluya a todos. 


\section{La otra revolución educativa ${ }^{1}$}

\section{The other educational revolution}

Mientras en los últimos tres años hemos visto nacer y morir de inanición una postulada Revolución educativa, otra revolución silenciosa, pero de mayor fuerza y trascendencia, se va gestando en la sociedad mexicana; el individuo y las instancias intermedias están asumiendo su papel. En el contexto de esta revolución de la organicidad social, se plantean cambios fundamentales en el sistema educativo. Estos pueden sintetizarse en una triple revolución copernicana que cambie los centros de gravitación: poner el sistema educativo al servicio del alumno y de la sociedad; poner al maestro en el centro del proceso educativo; y centrar la educación en un saber integrador, significativo y transformador.

\section{CAMBIAR EL SISTEMA EDUCATIVO, INVERTIR LAS CLIENTELAS}

Por ser la educación un proceso cultural por medio del cual cada grupo humano transmite a la nueva generación lo mejor de la herencia del grupo, la estructura educativa del Estado debe estar al servicio de la sociedad y en intercomunicación con ella. En materia de derechos primarios del individuo y de la familia, el Estado cumple un papel subsidiario, y los servicios que aporta complementan y no sustituyen a los sujetos primarios de los derechos. Los valores compartidos socialmente tienen su raíz en el consenso social y no en la autoridad del Estado. Consecuentemente, el aparato educativo debe estar al servicio de los educandos y de sus padres, las energías de los maestros deben orientarse a lograr la aprobación social, comenzando por la comunidad educativa en la que trabaja. La flecha que indica el flujo de los intereses en juego debe apuntar hacia el educando y su comunidad original y no hacia el secretario y demás autoridades. La satisfacción del secre-

${ }^{1}$ Trabajo aparecido originalmente en Revista Latinoamericana de Estudios Educativos vol. XV, núm. 4, 1985, pp. 5-8. 
tario deben ser los buenos resultados educativos, evaluados por toda la sociedad a partir del núcleo familiar. La unidad nacional se constituye desde lo individual y diverso: de la riqueza de los individuos, los estilos y las diferencias regionales que en la libertad comparten lo común nacional. El estilo de vida compartido, y no los controles artificiales, dan fuerza a una nación. Un indicador fundamental de salud social es la dirección en la que huyen los recursos públicos, humanos y financieros. ¿Sirven a los intereses de las personas o se sirven de las personas?

\section{REVALORAR AL MAESTRO}

Conforme ha aumentado el número de maestros, ha ido disminuyendo la proporción de verdaderos maestros; ha descendido notablemente la motivación personal, la seriedad profesional y, consecuentemente, la estima social del maestro. Muchos de ellos optaron por el magisterio por falta de mejores oportunidades, y un número considerable está solo de paso en busca de superación profesional o económica. Pero en los problemas del magisterio, más importantes que las raíces de tipo personal, son las causas de tipo estructural: al maestro en México se le controla como clientela política y se le automatiza como burócrata de la enseñanza. Se necesitan maestros con vocación que quieran, sepan, y puedan vivir gratificantemente el arte de enseñar y de educar. Sin embargo, para que esto sea posible es necesario que la estructura laboral, administrativa y curricular esté al servicio del maestro. En la realidad la estructura actual utiliza al maestro o, en el mejor de los casos, lo cosifica en la pobreza de un orden meticuloso, formalista, impositivo y despersonalizado. Si vamos a tener una mejor educación, es necesario que el proceso educativo respete al maestro y tenga confianza en él como creador de cultura, productor de ciencia, generador de lenguaje y promotor eficaz del conocimiento significativo. La estructura normativa solo debe dar cauce a la vida, no sustituirla ni momificarla. En la actualidad, un gran número de maestros son repetidores angustiados, frustrados o aburridos de cosas sin valor que otros a su vez les han repetido; tenemos un sistema de repeticiones a la " $n$ " potencia. Repeticiones muertas en lugar de creatividad personal viva. La 
verdadera estima del maestro, preocupación por la educación y amor al país, no está en ocultar los problemas sino en diagnosticarlos y ayudar en la búsqueda de los auténticos remedios. Como verdadero ser humano el maestro no necesita demagogia, sino auténtico respeto.

\section{REENCONTRAR EL SENTIDO DE LOS APRENDIZAJES}

No se exagera cuando se afirma que en materia curricular y normas de acreditación, lo único claro es que ya nada está claro. Quedan en el sistema educativo efectos de tantos implícitos, anacronismos, modas, reformas, tendencias pedagógicas, revoluciones educativas, luchas de facciones y manejos políticos que resulta imposible saber para qué objeto está diseñado este extraño conglomerado. Más difícil aún es intentar evaluar su eficacia educativa y prácticamente imposible hablar siquiera de modificarla. Los medios han sustituido a los fines. Pero si queremos una auténtica educación y devolver su valor al magisterio, es indispensable replantear, libre y creativamente, el papel del conocimiento. Volver al origen, revivir la aventura del conocimiento, dar importancia al conocimiento personalizado, significativo y orgánico. Volver también a generar cultura desde el microcosmos de cada persona particular en la trama vital de la lengua materna, clave de la autoimagen y vehículo primigenio de la comunicación. Aprender antes que nada, en el contexto de la propia comunidad, el arte de apropiarse, sapiencialmente, las relaciones con el hábitat, con el mundo de las personas y con la imagen interior del propio yo. Desde lo propio vitalmente poseído, podremos relacionarnos con toda persona y con toda cultura. Podemos ser universales desde nuestra particularidad. Un nuevo sentido del aprendizaje supone una manera nueva también de ejercer el magisterio, y un cambio de prioridades en la estructura educativa. Tres cambios de gravitación de intereses que se refuerzan y se necesitan. En resumen, hoy es necesario replantearlo todo. Hacer balance de todo lo anteriormente realizado y planear con conciencia de lo propio, pero con creatividad y libertad.

Hay ideas y posturas que en su momento fueron de avanzada, pero hoy forman parte del pasado, bagaje del conservaduris- 
mo actual. Frente a la inercia del pasado, hay que plantear las posibilidades fecundas del futuro. Querer el cambio, imaginar creativamente los procesos que lo hagan posible y tener la habilidad y perseverancia para hacerlos posibles desde las estructuras administrativas de hoy. Es una enorme tarea, pero son mayores las potencialidades de este país.

Centro de Estudios Educativos 